\section{OUTCOMES FOLLOWING TRANSCATHETER AORTIC VALVE IMPLANTATION COMPARING EDWARDS SAPIEN WITH MEDTRONIC COREVALVE REVALVING SYSTEM DEVICES: RESULTS FROM THE MILAN REGISTRY}

doi:10.1136/heartjnl-2012-301877b.40

G L Buchanan,* A Chieffo, M Montorfano, F Maisano, A Latib, M Cioni, F Figini, M Carlino, R D Covello, A Franco, C Gerli, A Grimaldi, G La Canna, P Spagnolo, 0 Alfieri, A Colombo. San Raffaele Scientific Institute, Milan, Italy

Background To assess clinical outcomes of transcatheter aortic valve implantation comparing Medtronic CoreValve ReValving System ${ }^{\circledR}$ with Edwards SAPIEN XT.

Methods All consecutive patients in our center with aortic stenosis treated with transfemoral Medtronic CoreValve ReValving System ${ }^{\circledR}$ (MCV) from November 2009 to September 2011 (learning curve patients excluded) or Edwards SAPIEN XT (ESV) from April 2010 to September 2011 when the device became available were included. Results In total, there were 192 patients in this analysis. The overall mean age was $79.4 \pm 8.1$ years, logistic EuroSCORE $21.1 \pm 15.9 \%$ and STS-PROM score $8.8 \pm 8.6 \%$. The MCV group consisted of a greater proportion of males $(60.3 \%$ vs $43.7 \% ; p=0.026)$ with a corresponding larger aortic annulus size $(24.7 \pm 2.0$ vs $23.4 \pm 1.7$; $\mathrm{p}<0.001)$. The median clinical follow-up length was 171 (IOR 54-357) days. 30 -day all cause mortality was $4.0 \%$, myocardial infarction rate $1.0 \%$ and stroke $0.5 \%$, with no differences between valve types. Lifethreatening bleeding occurred in $14.7 \%$ and $11.5 \%$ had a major vascular complication. There were no differences in the combined safety endpoint at 30 days (ESV $72.2 \%$ vs MCV $71.9 \%$; $=0.936$ ). However, there was a significantly higher rate of device success among the ESV group ( $98.3 \%$ vs $90.4 \%$; $=0.012$ ) with additionally a significantly higher rate of conduction disturbances/arrhythmia $(31.5 \%$ vs $16.0 \% ; \mathrm{p}=0.011)$ as well as pacemaker implantation (28.8\% vs $5.0 \%$; $\mathrm{p}<0.001$ ) with MCV compared with ESV.

Conclusions In our single center experience, transcatheter aortic valve implantation was a relatively safe and effective procedure utilising both commercially available devices. However, there was an increased incidence of arrhythmia and pacemaker implantation in the MCV group.

\section{SERIAL CHANGE IN HEALTH RELATED QUALITY OF LIFE OVER 1 YEAR FOLLOWING TRANSCATHETER AORTIC VALVE IMPLANTATION: PREDICTORS OF HEALTH OUTCOMES}

doi:10.1136/heartjnl-2012-301877b.41

${ }^{1} \mathrm{~T}$ A Fairbairn, * ${ }^{1} \mathrm{D} \mathrm{M}$ Meads, ${ }^{1} \mathrm{~A} N \mathrm{~N}$ Mather, ${ }^{1} \mathrm{M}$ Motwani, ${ }^{1} \mathrm{~S}$ Pavitt, ${ }^{1} \mathrm{~S}$ Plein, ${ }^{2} \mathrm{D} \mathrm{J}$ Blackman, ${ }^{1} \mathrm{~J} \mathrm{P}$ Greenwood. ${ }^{1}$ University of Leeds, Leeds, UK; ${ }^{2}$ Leeds General Infirmary, Leeds, UK

Introduction Severe aortic stenosis (AS) reduces the length and quality of a patient's life. Transcatheter Aortic Valve Implantation (TAVI) is superior to standard medical therapy and non-inferior to Surgical Aortic Valve Replacement (SAVR) for 1-year mortality. HRQOL is an important outcome measure, for which there is limited evidence in TAVI populations. This study aimed to assess serial changes in patient health related quality of life (HROOL) over time and identify predictors of patient benefit.

Method 102 (age $80 \pm 0.6$ years, female 51\%) attending for TAVI consented to participate. Two HROOL questionnaires, the SF12v2 with physical and mental component summaries (PCS and MCS) and the EQ-5D (with Visual Analogue Scale; VAS) were completed at baseline, 30 days, 6 and 12 months. A SF-6D utility measure was calculated from the SF12 survey.

Results HRQOL significantly improved over 12 months (PCS, $p=0.002$; EQ-5D, $p=0.02$; VAS, $p=0.01$; SF-6D $p=0.048)$. The greatest change occurred from baseline to 30 days $(p<0.001)$ with further significant increases to 6 months $(p<0.01)$. An insignificant decline occurred between 6 and 12 months ( $p>0.05)$, Abstract 041 table 1. Female gender $(p<0.05)$, age $\geq 80$ years $(p<0.05)$, previous MI $(p<0.04), C K D(p<0.05)$, pulmonary hypertension $(p=0.04)$ and lower operator experience $(p<0.001)$ were independent predictors of a smaller improvement in HRQOL, Abstract 041 figure 1.

\section{Abstract 041 Table 1}

\begin{tabular}{lllllll}
\hline \multirow{2}{*}{$\begin{array}{l}\text { Health } \\
\text { survey }\end{array}$} & US norm* & $\begin{array}{l}\text { Baseline } \\
\mathbf{n = 9 9}\end{array}$ & $\begin{array}{l}\mathbf{3 0} \text { days } \\
\mathbf{n = 9 0}\end{array}$ & $\begin{array}{l}\mathbf{6} \text { months } \\
\mathbf{n = 7 0}\end{array}$ & $\begin{array}{l}\mathbf{1 2} \text { months } \\
\mathbf{n = 5 5}\end{array}$ & $\mathbf{p}$ Value $\dagger$ \\
\hline PCS & $37.3 \pm 3$ & $29.5 \pm 9$ & $36.4 \pm 9$ & $38.3 \pm 11$ & $35.8 \pm 10$ & 0.002 \\
MCS & $51 \pm 3$ & $45 \pm 12$ & $46.4 \pm 13$ & $47.4 \pm 11$ & $45.2 \pm 11$ & 0.45 \\
EQ-5D & $0.66 \pm 0.2$ & $0.54 \pm 0.3$ & $0.65 \pm 0.3$ & $0.68 \pm 0.3$ & $0.59 \pm 0.3$ & 0.02 \\
VAS & $0.53 \pm 7$ & $51.1 \pm 21$ & $61.4 \pm 21$ & $68.2 \pm 20$ & $56.2 \pm 28$ & 0.01 \\
SF-6D & $0.72 \pm 0.1$ & $0.60 \pm 0.1$ & $0.66 \pm 0.1$ & $0.68 \pm 0.1$ & $0.62 \pm 0.1$ & 0.048 \\
\hline
\end{tabular}

Values are mean \pm SD.

*US Norms are reported for a US population stratified by age (80-89 years).

t $p$ Values are reported for a change in health and were calculated by repeated measures ANOVA. Numbers reflect the patients who completed the 4 time-points questionnaires entered into the analysis.

PCS, physical component score; MCS, mental component score; VAS, visual analogue score.

Conclusions HRQOL significantly improves early following TAVI and is maintained out to 1 year. Patient and procedural predictors of health benefit at 1 year may help patients and physicians make a fully informed decision during the TAVI selection process.

\section{SF 12 and VAS}

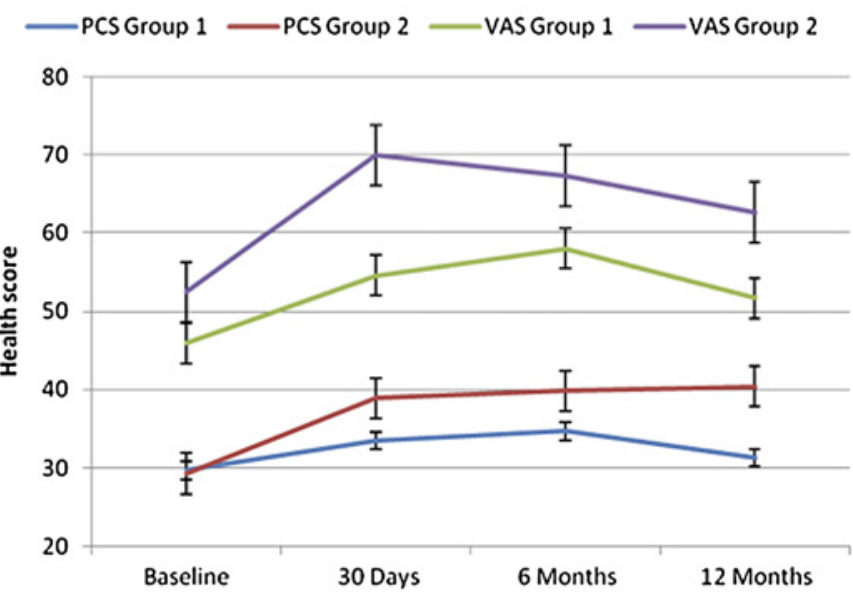

EQ-5D and SF-6D

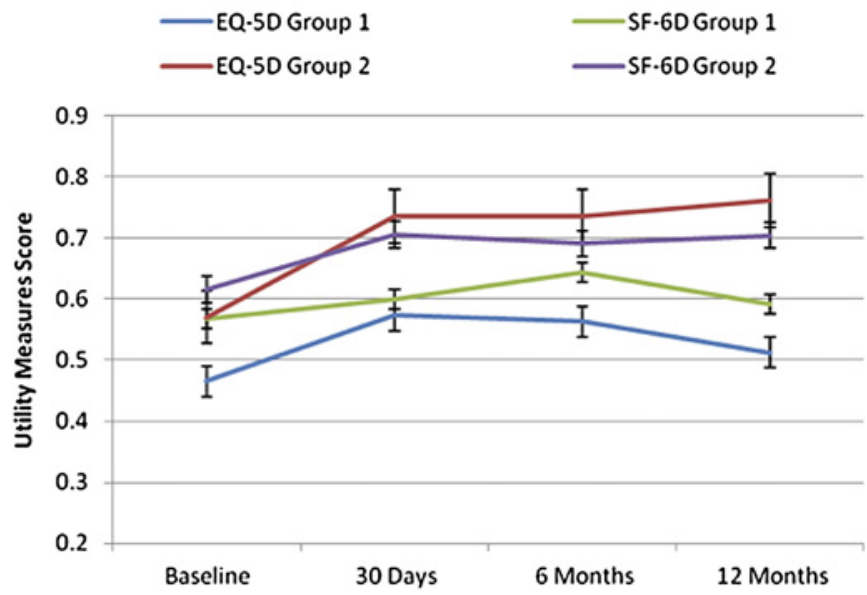

Abstract 041 Figure 1 Operation order. 